\title{
Peripheral neuropathy as the presenting feature of tyrosinaemia type I and effectively treated with an inhibitor of 4-hydroxyphenylpyruvate dioxygenase
}

\author{
T C Gibbs, J Payan, E M Brett, S Lindstedt, E Holme, P T Clayton
}

\begin{abstract}
A 21 month old girl presented with a short history of frequent falls and a right sided foot drop. She went on to suffer recurrent episodes of distal weakness in her arms and legs with hyporeflexia. Electrophysiological studies were consistent with inflammatory demyelinating polyradiculoneuropathy (IDP) and treatment with corticosteroids appeared to lead to an improvement. However, the development of hypertension, evidence of tubulopathy, and hepatomegaly led to reevaluation. A diagnosis of type I tyrosinaemia was made, based on increased urinary excretion of succinylacetone and decreased activity of fumarylacetoacetase in her cultured skin fibroblasts. A low tyrosine diet did not prevent lifethreatening exacerbations of neuropathy but intravenous haemarginate appeared to aid her recovery from one exacerbation. An immediate improvement in strength was seen after starting treatment with 2-(2-nitro-4-trifluoro-methylbenzoyl)-1,3-cyclohexanedione (NTBC), an inhibitor of 4-hydroxy-phenylpyruvate dioxygenase. A liver transplant was performed but the patient died of immediate postoperative complications. Tyrosinaemia needs to be considered in a child with recurrent peripheral neuropathy because (i) the signs of liver disease and renal tubular dysfunction may be subtle; (ii) acute exacerbations may be life threatening; (iii) specific forms of treatment are available.
\end{abstract}

$(\mathcal{F}$ Neurol Neurosurg Psychiatry 1993;56:1129-1132)

Tyrosinaemia type I (McKusick no 276700) usually presents with symptoms attributable to hepatic or renal tubular dysfunction, or both. ${ }^{1}$ Tyrosinaemia can be detected by neonatal amino acid screening, ${ }^{2}$ or by more specific screening procedures based on the accumulation of succinylacetone or its effects. ${ }^{34}$ Succinylacetone, which accumulates in this disorder, is a potent inhibitor of porphobilinogen synthase and patients usually show increased urinary excretion of 5-aminolaevulinic acid ( $\delta$-ALA).

Neurological crises resembling acute por- phyria have been well described in children with tyrosinaemia, ${ }^{5-7}$ but we are only aware of one case in which a neurological symptom (ataxia) was the presenting feature. ${ }^{8}$ This report describes a patient with tyrosinaemia type $I$ in whom recurrent weakness due to a peripheral neuropathy was the presenting symptom. A number of different forms of treatment were attempted and the results are presented.

\section{Case report}

Our patient was the first child born to unrelated Asian parents. There was no family history of neurological disease. Neonatal screening excluded hyperphenylalaninaemia and hypothyroidism but the methods used were not capable of picking up tyrosinaemia. The patient had started walking at 16 months and was apparently well until 21 months of age. At about this time her parents noticed she tended to fall over and had a right-sided foot drop.

At 26, 29, and 32 months, she had an acute illness characterised by a fever, irritability, leg pains, a right-sided limp, and colicky right iliac fossa pain. Examination revealed distal weakness in her arms and legs, bilateral foot drop, and decreased reflexes with absent ankle jerks. Nerve conduction studies were performed at 30 and 33 months (see below). A diagnosis of a chronic relapsing form of polyneuropathy was made because of the nature and variability of the results of motor conduction studies and the persisting normality of sensory conduction. High dose daily oral corticosteroids led to an improvement in her symptoms. Any attempt to reduce the dose of prednisolone to less than $17.5 \mathrm{mg}$ per day over the next 18 months led to exacerbation of her symptoms. The response to treatment was gratifying but certain features of the case remained unexplained as indicated in table 1 ( 26 months, 29 months).

At 3.5 years the patient was noted to have developed palmar erythema. She was cushingoid, hypertensive (170/120), and had stopped growing. Examination revealed clinical cardiomegaly and echocardiography confirmed biventricular hypertrophy. A firm liver edge was palpable $2.5 \mathrm{~cm}$ below the costal margin. She had a wide-based gait, distal muscle weakness with areflexia, and flexor 
Table 1 Non-neurological features of tyrosinaemia which were detected at various stages of the patient's illness

\begin{tabular}{|c|c|c|c|}
\hline $\begin{array}{l}\text { Age } \\
\text { (months) }\end{array}$ & Signs of liver disease & $\begin{array}{l}\text { Signs of renal tubular } \\
\text { dysfunction and } \\
\text { hypophosphataemic } \\
\text { bone disease }\end{array}$ & $\begin{array}{l}\text { Evidence of deranged } \\
\text { tyrosine metabolism }\end{array}$ \\
\hline 26 & $\begin{array}{l}\text { Hepatomegaly } \\
\text { Coarse, granular liver } \\
\text { on ultrasound } \\
\uparrow \text { liver alkaline phosphatase }\end{array}$ & $\begin{array}{l}\mathrm{K}^{+} 2.5 \mathrm{mM} \\
\uparrow \text { bone alkaline phosphatase } \\
\mathrm{e}\end{array}$ & $\uparrow$ urine tyrosine \\
\hline 29 & & $\begin{array}{l}\text { Urine glucose } 1 \mathrm{mM} \\
\uparrow \text { urine lactate }\end{array}$ & $\begin{array}{l}\uparrow \text { urine 4-hydroxyphenyl- } \\
\text { lactate }\end{array}$ \\
\hline \multirow[t]{2}{*}{42} & $\begin{array}{l}\text { Palmer erythema } \\
\text { Hepatomegaly } \\
\text { Imaging suggestive of } \\
\text { cirrhosis }\end{array}$ & $\begin{array}{l}\mathrm{K}+3.3 \mathrm{mM} \\
\text { Phosphate } 0.38 \mathrm{mM} \\
\text { Tubular reabsorption of } \\
\text { phosphate } 40 \% \\
\uparrow \text { urine albumin/creatinine } \\
\text { ratio }\end{array}$ & $\begin{array}{l}\text { Plasma tyrosine } 348 \mu \mathrm{M} \\
\uparrow \text { urine 4-hydroxyphenyl- } \\
\text { lactate and -pyruvate }\end{array}$ \\
\hline & $\begin{array}{l}\text { Prothrombin ratio } 17 / 12 \\
\text { a-fetoprotein } 634 \mathrm{kU} / 1 \\
\text { (normal }<10 \text { ) }\end{array}$ & $\begin{array}{l}\text { Glycosuria } \\
\text { Metabolic acidosis (pH 7.3, } \\
\text { base excess - 10; urine pH 6.6) } \\
\text { Generalised aminoaciduria } \\
\text { Widening of epiphyseal plates, } \\
\text { osteoporosis, pathological } \\
\text { fracture }\end{array}$ & $\begin{array}{l}\uparrow \text { urine succinylacetone } \\
\downarrow \text { fibroblast fumarylaceto- } \\
\text { acetase }\end{array}$ \\
\hline
\end{tabular}

plantar responses. The hepatomegaly, and the previous results suggesting renal tubular dysfunction and impaired metabolism of tyrosine and phenolic acids, led to consideration of the diagnosis of tyrosinaemia and this was confirmed by analysis of urinary organic acids by gas chromatography-mass spectrometry. This showed greatly increased excretion of succinylacetone. Fumarylacetoacetase activity in cultured skin fibroblasts (Professor Berger, Utrecht) was $0.14 \mathrm{nmol} / \mathrm{min} / \mathrm{mg}$ protein (normal range $1 \cdot 3-2 \cdot 7)$. Further investigations showed more abnormalities compatible with tyrosinaemia (table 1, 42 months). Urinary $\delta$ ALA was $84 \cdot 1 \mu \mathrm{mol} / 1$ (reference range $0-34$ ) and quantitative urinary porphobilinogen was $2.5 \mu \mathrm{mol} / 1(0-8 \cdot 8)$. Investigation of the hypertension showed plasma renin was $>4000 \mathrm{U} / 1$ (reference range 110-2610), plasma aldosterone $928 \mathrm{pmol} / 1$ (69-946). At the same time of sampling plasma noradrenaline was $941 \mathrm{pg} / 1(<1000)$.

The patient was treated for tyrosinaemia with supplements of phosphate, potassium, and bicarbonate (for the renal Fanconi syndrome) and a reduced tyrosine diet. The steroids were slowly withdrawn. Her hypertension was controlled with propranolol and hydrallazine.

Six weeks later she was readmitted with severe weakness of her shoulder girdle, a weak nasal voice, and obvious paradoxical respiration. Radiological screening of the chest confirmed dampened excursions of both diaphragms leading to decreased lung volumes when lying supine. Urgent liver transplantation was considered but the patient's blood group was B rhesus positive and no compatible donor organ became available. In view of the previous apparent response to steroids, she was restarted on prednisolone $10 \mathrm{mg}$ daily which led to some improvement in her shoulder girdle movement but not her paradoxical respiration.

Treatment with haemarginate was started; $3 \mathrm{mg} / \mathrm{kg}$ was given intravenously over 15 minutes once a day for three weeks. The dose of prednisolone was increased to $15 \mathrm{mg}$ daily
Table 2 Effect of 2 weeks of NTBC treatment on biochemical parameters

\begin{tabular}{llll}
\hline Analyte & $\begin{array}{l}\text { Pre- } \\
\text { treatment }\end{array}$ & $\begin{array}{l}\text { Post- } \\
\text { treatment }\end{array}$ & $\begin{array}{l}\text { Normal } \\
\text { range }\end{array}$ \\
\hline $\begin{array}{l}\text { Urine succinylacetone } \\
\text { (mmol/mol creatinine) }\end{array}$ & 25 & nd & nd \\
$\begin{array}{l}\text { Urine } \delta \text {-ALA } \\
(\mu \mathrm{mol} / \mathrm{l})\end{array}$ & 447 & 18 & $<34$ \\
$\begin{array}{l}\text { Serum } a \text {-fetoprotein } \\
(\mathrm{kU} / \mathrm{l})\end{array}$ & 269 & 90 & $<10$ \\
$\begin{array}{l}\text { Plasma tyrosine } \\
(\mu \mathrm{mol} / \mathrm{l})\end{array}$ & 192 & 494 & $30-120$ \\
$\begin{array}{l}\text { Erythrocyte porpho- } \\
\text { bilinogen synthase } \\
(\mathrm{nmol} / \mathrm{min} \times \mathrm{g} \mathrm{Hb})\end{array}$ & $\mathrm{ND}$ & 88 & $35-75$ \\
\hline
\end{tabular}

nd $=$ not detectable. ND = not done.

and the low protein diet was changed to a low phenylalanine, low tyrosine diet. After two weeks the patient's voice had become louder and a normal breathing pattern had returned. Thereafter power in the muscles of the shoulder girdle and upper limbs gradually improved. She then began complaining of burning pain in the feet made worse by weight bearing. The prednisolone dose was reduced to $10 \mathrm{mg} / 7.5 \mathrm{mg}$. The pain in the feet gradually subsided and, apart for sustaining a fracture of the right femur, she remained well for three months (albeit with evidence of persistent neuropathy in the lower limbs).

From four years to five years six months the patient had four further acute episodes of pyrexia, abdominal and leg pain, hypertension, and weakness of both legs. On one occasion she developed a weak voice, stridor, and dyspnoea. The episodes were treated with an increase in her antihypertensive medication and steroid dosage. At the age of five years six months the patient was started on treatment with oral NTBC [2-(2-nitro-4-trifluoromethylbenzoyl)-1,3-cyclohexanedione] at a dose of $0.6 \mathrm{mg} / \mathrm{kg}$ once daily. ${ }^{9}$ The morning after starting treatment, her parents noted a dramatic improvement in her strength, her activity, and her appetite. Instead of being just able to walk with a wide-based unsteady gait, she could walk quite rapidly and steadily and could walk down stairs; a few days later she was able to run. Physical examination confirmed an increase in power in both upper and lower limbs, although the lower limbs remained areflexic. Two weeks after starting treatment, there were clear signs of biochemical improvemement (table 2). The nerve conduction studies, however, were worse than at 45 months.

When our patient was five years nine months old a compatible liver became available. Because of uncertainty about long term treatment with NTBC liver transplantation was performed. Unfortunately the patient died of postoperative complications.

\section{Results of nerve conduction studies}

These are summarised in table 3 . The first nerve conduction study was performed at 30 months. The very small mildly delayed evoked muscle action potentials (CMAP) 
Table 3 Results of electromyography and nerve conduction studies

\begin{tabular}{|c|c|c|c|c|}
\hline Age (months) & 30 & 33 & 45 & Normal $^{10}$ \\
\hline $\begin{array}{l}\text { Right median MNAP }(\mu \mathrm{V}) \\
\text { (stim wrist, rec elbow) SCV } \\
\text { Right thenar CMAP (stim wrist) }\end{array}$ & 44 & $\begin{array}{r}130 \\
63\end{array}$ & ND & $\begin{array}{l}\geq 30 \\
\geq 50\end{array}$ \\
\hline $\begin{array}{l}\text { Right thenar CMAP (stim wrist) } \\
\text { amplitude (mV) } \\
\text { latency (ms) }\end{array}$ & $\begin{array}{l}0.07 \\
3.4\end{array}$ & $\begin{array}{l}0.8 \\
6.5\end{array}$ & $\begin{array}{l}2 \cdot 5 / 2 \cdot 0 \ddagger \\
3 \cdot 2\end{array}$ & $\begin{array}{l}\geq 4 \\
\leq 2 \cdot 5\end{array}$ \\
\hline $\begin{array}{l}\text { F latency (ms) } \\
\text { Median n MCV (m/s) } \\
\text { (elbow-wrist) }\end{array}$ & 45 & 50 & $\begin{array}{l}20 \cdot 5 \\
35^{\star}\end{array}$ & $\begin{array}{l}\mathrm{NK} \\
\geq 46^{\star}\end{array}$ \\
\hline $\begin{array}{l}\text { Right abductor hallucis CMAP (stim ankle) } \\
\text { amplitude (mV) } \\
\text { latency (ms) } \\
\text { F latency (ms) }\end{array}$ & $\begin{array}{l}0 \cdot 15 \\
3 \cdot 4 \\
32\end{array}$ & ND & ND & $\begin{array}{l}\geq 2 \cdot 0 \\
\leq 3 \cdot 5 \\
\leq 30\end{array}$ \\
\hline $\begin{array}{l}\text { Left abductor hallucis CMAP } \\
\text { amplitude (mV) } \\
\text { latency (ms) }\end{array}$ & $0 \cdot 16$ & absent & $\begin{array}{r}2 \cdot 8 \\
4 \cdot 0\end{array}$ & $\begin{array}{l}\geq 2 \cdot 0 \\
\leq 3 \cdot 5\end{array}$ \\
\hline $\begin{array}{l}\text { F latency (ms) } \\
\text { Left medial popliteal } \mathrm{MCV}(\mathrm{m} / \mathrm{s}) \\
\text { (popliteal fossa-ankle) }\end{array}$ & $\begin{array}{l}31 \\
40\end{array}$ & & $\begin{array}{l}38 \\
25\end{array}$ & $\begin{array}{l}\leq 30 \dagger \\
\geq 41^{\star}\end{array}$ \\
\hline
\end{tabular}

*Age related. †No change in child's height. $¥$ A smaller desynchronised potential when stimulating at elbow. $\mathrm{ND}=$ not done. $\mathrm{NK}=$ not known. $\mathrm{CMAP}=$ evoked compound muscle action potential. $\mathrm{APB}=$ abductor pollicis brevis. $\mathrm{MNAP}=\operatorname{mixed}$ nerve action potential. $\mathrm{SCV}=\operatorname{maxi}-$ mum sensory conduction velocity. $\mathrm{MCV}=$ maximum motor conduction velocity.

were in marked contrast to the normal nerve action potential (MNAP). Three months later the thenar CMAP was larger than before but much more delayed. A foot muscle potential was no longer obtainable. The MNAP was still normal and much larger than before.

A third nerve conduction study was undertaken at age 45 months. The amplitude of the thenar MAP had increased to more than half the normal minimum but showed a $20 \%$ decrement when the median nerve was stimulated at the elbow. Distal latancy was now nearly normal but a pronounced fall in motor conduction velocity had occurred. The previously absent foot muscle CMAP was now normal but here also motor conduction velocity had fallen from its previously normal level. The $\mathrm{F}$ wave latency was increased.

At 66 months (two weeks after starting NTBC), nerve conduction studies showed that there had been a marked deterioration over the 21 month period. It was no longer possible to record foot muscle responses and the previously normal nerve action potential in the right arm had disappeared. Median nerve motor conduction was extremely slow.

\section{Discussion}

Tyrosinaemia is not usually considered in patients presenting with peripheral neuropathy. However, it is becoming clear that this and other neurological presentations such as ataxia are possible in the first three years of life. ${ }^{58}$ In keeping with the description by the Quebec group 5 of 20 patients with tyrosinaemia who had neurological crises, our patient often had a fever preceding or accompanying her episodes of peripheral neuropathy. Initially, pain was not an obvious feature but later, poorly localised leg pains and abdominal pain were constantly present at the onset of an attack.

Neurological examination of our patient demonstrated only the signs of a peripheral neuropathy, unlike previously described cases, in which there were signs of upper motor neuron involvement (hypertonia, hyperreflexia, and ankle clonus)..$^{5-7}$ Sustained arterial hypertension has been described in up to $30 \%$ of patients with neurological crises $^{5-7}$ and was a prominent feature in our patient. As in the patient described by Strife, our patient had activation of the renin-aldosterone pathway.

The results of the first nerve conduction study pointed to a severe and apparently exclusively motor neuropathy. Such a picture developing acutely or subacutely usually points to an acquired inflammatory demyelinating polyradiculoneuropathy (IDP). Support for this diagnosis came with the fluctuations recorded at the second and third studies, thus: (1) an increase in the amplitude of the thenar CMAP was accompanied by an increase in latency, which subsequently returned to normal; (2) the median MCV, normal in the first two studies, had slowed markedly by the third; (3) an abductor hallucis CMAP absent at the second study was normal at the third, but the medial popliteal MCV had fallen and the $F$ wave was delayed. Such variation at successive investigations is familiar in adult IDP. It is clear from our studies on this patient that in a young child with electrophysiological features suggesting IDP, the diagnosis of tyrosinaemia must be considered. With hindsight it can be seen that there were important clues to the diagnosis of tyrosinaemia in our patient during the second year of life (table 1).

The mechanism of neural damage in tyrosinaemia remains to be fully elucidated. In tyrosinaemia there is accumulation of $\delta$-ALA as a result of inhibition of $\delta$-ALA dehydratase by succinylacetone, and this compound ( $\delta$-ALA) may contribute to neurotoxicity. This has led to comparisons between the neural damage of porphyria and that of tyrosinaemia. However, in our patient (as in previously described patients with neurological crises) the $\delta$-ALA was raised during remission as well as at the time of crisis. There are also important electrophysiological differences between the neuropathy of porphyria and that of tyrosinaemia. The fluctuating electrophysiological picture and the marked reduction in motor conduction velocity we obtained are usually strongly suggestive of a primary demyelinating process. In contrast to this, the key feature of prophyria is the preservation of motor conduction velocity since it is a pure axonal neuropathy.

Spontaneous improvement can be expected in most children who suffer a neurological crisis in tyrosinaemia. Hence it is difficult to assess the efficacy of treatment. Prednisolone appeared to have a beneficial effect on several occasions in our patient (which would perhaps support the conclusions that a primary demyelinating process was responsible for the neuropathy). Haemarginate (which inhibits the synthesis of $\delta$-ALA from glycine and succinate) also seemed to aid recovery from a severe crisis and this lends support to the idea that $\delta$-ALA accumulation is at least partly responsible for the neural damage. 
NTBC was the drug which had the clearest beneficial effect clinically. By inhibiting 4hydroxyphenylpyruvate dioxygenase, NTBC reduces the production of succinylacetone; this in turn releases the inhibition of $\delta$-ALA dehydratase (porphobilinogen synthase) and prevents the accumulation of $\delta$-ALA. ${ }^{9}$ The effect of NTBC on neurological function was apparent within days (even hours) as was the effect on urinary succinylacetone and $\delta$-ALA. Despite the clinical improvement, electrophysiology indicated a severely depressed motor conduction velocity. Perhaps normalisation of $\delta$-ALA levels improves axonal function rapidly but demyelination takes much longer to recover.

Neurological crises have not been reported in children with tyrosinaemia who have had a liver transplant and children who have been rescued from a ventilator-dependent state by transplantation (Mitchell et $a l^{5}$ and unpublished observations). Thus, one indication for liver transplantation has been the presence of or risk of porphyric crises. The observations in this case indicate that NTBC is very effective in treating the neuropathy and therefore may make liver transplantation unnecessary on this indication. Other indications for liver transplantation are liver failure and the fact that children with tyrosinaemia are at considerable risk from developing hepatocellular carcinoma. The risk is removed (and carcinoma which has not metastasised can be cured) by liver transplantation. However, liver transplantation still only offers an $85 \%$ five year survival rate. We do not know whether NTBC will prevent the development of hepatocellular carcinoma or end stage liver disease. These questions will only be answered by careful clinical trials.
In summary, this report indicates the need for a careful search for the physical signs of tyrosinaemia (hepatomegaly, rickets, cardiomegaly, hypertension) and for the biochemical abnormalities (acidosis, hypophosphataemia, prolonged clotting times, mildly raised transaminases, phenolic acids in the urine, and raised tyrosine) in a child with peripheral neuropathy. If there is any suggestion of these abnormalities urinary succinyl acetone should be measured so that specific therapy can be instituted.

This work was supported by donations to the Institute of Child Health collected by parents of children with tyrosinaemia, by a donation from Imperial Chemical Industries and naemia, by a donation from Imperial Chemical Industries and
by a grant from the Swedish Cancer Society (project number by a grant).
3301 .

1 Goldsmith LA, Laberge C. Tyrosinaemia and related disorders. In: Scriver CR, Beaudet AL, Sly WS, Valle D, eds. The metabolic basis of inherited disease. VIth Edition, New York: McGraw Hill, 1989.

2 Grenier A, Laberge C. A modified fluorimetric method for tyrosine determination in blood spotted on paper; a mass screening procedure for tyrosinaemia. Clin Chim Acta 1974;57:71-5.

3 Greiner A, Lescault A, Laberge C, Gagné R, Mamer O. Detection of succinylacetone and the use of its measurements in mass screening for hereditary tyrosinaemia. Clin Chim Acta 1982;123:93-9.

4 Holme E, Lindstedt S. Neonatal screen for hereditary tyrosinaemia type I. Lancet 1992;340:850.

5 Mitchell G, Larochelle J, Lambert $M$, et al. Neurologic crises in hereditary tyrosinemia. $N$ Engl $\mathcal{F}$ Med 1990;322: 432-7.

6 Strife CF, Zuroweste EL, Emmett EA, et al. Tyrosinemia with acute intermittent porphyria: aminolevulinic acid
dehydratase deficiency related to elevated urinary aminolevulinic acid levels. $\mathcal{f}$ Pediatr 1977;90:400-4.

7 Rank JM, Leone AP, Payne W, et al. Hematin therapy for the neurological crisis of tyrosinemia. $\mathcal{F}$ Pediatr 1991; 118:136-9.

8 Burlina A, Bordugo A, Dussini N, et al. Atassia acute in trosinaemia tipo I. Nuovo aspetto di una rara malattia. Riv Ital Pediatr 1991;17:632-4.

9 Linstedt S, Holme E, Lock EA, Strandvik B. Treatment of hereditary tyrosinaemia type I by inhibition of 4hydroxyphenylpyruvate dioxygenase. Lancet 1992;340: 813-7.

10 Payan J. Clinical electromyography in infancy and childEdinburgh: Churchill Livingstone, 1990;797-829. 